Celso Lafer, Ph. D. (Cornell), professor de Direito Internacional e de Filosofia do Direito na Universidade de São Paulo.

\title{
Direito e poder na reflexão de Miguel Reale'
}

1. Este trabalho é a versão revista de conferência pronunciada em 10/6/81 no seminário sobre a obra do professor Miguel Reale, promovido pela Universidade de Brasília. Retoma, com significativos acréscimos, a comunicação apresentada em outubro de 1980 no 1 ? Encontro Brasileiro de Filosofia do Direito, realizado em João Pessoa (PB).

2. REALE, Miguel. Filosofia do direito. 8. ed. rev. São Paulo, Saraiva, 1978. v. 1, p. 23.

3. LAFER, Celso. Saudação do bacharelando Celso Lafer. Revista da Faculdade de Direito da USP. São Paulo, 60 (1): 361-4, 1965.

4. ARENDT, Hannah. Willing. In: The life of the mind. New York, Harcourt, Brace Jovanovich, 1978. v. 2, p. 35$8,169,195-8$.

\section{Introdução}

No prefácio à primeira edição de sua Filosofia do Direito, que é de 1953, Miguel Reale, ao reafirmar a sua posição - expressa em Fundamentos do Direito, que data de 1940 - de que o Direito não é uma pura abstração lógica ou ética, destacada da experiência social, reiterou, como lema, o seu propósito juvenil de "teorizar a vida e viver a teoria na unidade indissolúvel do pensamento e da ação" 2 .

Sempre me causou impacto esta formulação de propósito que permeia todo o discurso de Miguel Reale, tanto que foi esse tema da oração com a qual o saudei, no segundo semestre de 1964, em nome de meus colegas - bacharelandos daquele ano da Faculdade de Direito da USP - quando ele recebeu o prêmio "Moinho Santista", na categoria de Ciências Juridicas. Naquela ocasião, numa quadra de intensos debates políticos, e procurando transcender a agenda do debate ideológico, tentei realçar a importância de um esforço que buscava amalgamar logos e pragma, e que não recusava enfrentar, no plano substantivo, as contradições entre pensamento e ação3. Dezessete anos depois, nesta semana dedicada à obra de Miguel Reale, em boa hora promovida pela Universidade de Brasília, volto ao tema, que também, por afinidade intelectual e inquietação pessoal, continua a me seduzir.

Existe na tradição ocidental, como observou Hannah Arendt, um antagonismo latente entre o "eu que pensa" e o "eu que quer". O tonus do eupensante é a serenidade, a "tranquillitas animae" de Leibniz, que provém da "acquiescentia in se ipso" spinoziana, alcançável por meio de um entendimento com a ordem do mundo. O tonus do eu que quer, ao contrário, é a tensão, provocada pela desordem das coisas, tensão que só é superável pela ação, pois a força da vontade só se revela no projeto, voltado para o futuro, uma vez que a vontade, quando quer retrospectivamente, percebe a sua impotência4. 
5. CZERNA, Renato Cirell. Esperienza e cultura in Miguel Reale. Rivista Internazionale di Filosofia del Diritto. 61 (4): 531-48, out./dez. 1979.

6. ARENDT, Hannah. The human condition. Chicago, The University of Chicago Press, 1958. p. 177-81.
Em Miguel Reale, o tradicional antagonismo entre o tonus do eu pensante e do eu que quer - que motivou a célebre afirmação de Marx, de que era necessária não apenas a interpretação do mundo mas também a sua transformação - foi fecundo, e sobretudo enriquecedor, de sua reflexão. Acredito que isto se deve, entre outras coisas a duas que me parecem fundamentais: a primeira é uma inquietação permanente com as possibilidades do conhecimento que em Reale se traduziu, enquanto leitor de Kant, na presença da razão, enquanto idéia regulativa, ainda que histórica e socialmente condicionada. A segunda radica-se numa atitude dialética, voltada para a percepção dos contrários e dos contraditórios, que para ele se coimplicam numa relação de mútua complementaridade. Esta atitude dialética permitiu a Miguel Reale lidar com as ambigüidades da ação, incorporando-as na sua reflexão - reflexão motivada por sincero e kantiano desejo de conhecimento.

Observa, neste sentido, Renato Czerna, que toda compreensão da experiência, para Miguel Reale, tem como condição de possibilidade do conhecimento o princípio transcendental, na tradição que remonta ao criticismo de Kant. Entretanto, a correlação sujeito-objeto do criticismo de Kant, em Reale, é modificada pelo princípio dialético da polarização, que na interfuncionalidade indissolúvel da relação sujeito-objeto significa, em última análise, uma reinterpretação nãoidealista do mais autêntico significado da doutrina de Kant. Daí uma visão imanentista da realidade, entendida como um dialético processo histórico cultural, que se insere no horizonte do racional5. É isto que, a meu ver, provoca um sempre presente parar para pensar aberto para o mundo que nos cerca e preocupado com o significado das coisas.

Esta combinatória de reflexão e ação, produto de uma inquietação básica, fundamentadora da personalidade de Miguel Reale, teve um efeito singular na sua obra e na qualidade de seu ensino, que ora desejo realçar.

Uma vida sem palavra e sem ação, argumenta Hannah Arendt, é uma vida morta para o mundo, pois deixa de ser uma vida vivida entre os homens. Com efeito, é através da palavra e da ação que os homens se distinguem, ao invés de serem apenas distintos uns dos outros, pois o ato humano primordial está na resposta à pergunta: "Quem sois?". A palavra e a ação desvendam o ser concreto, constituindo a modalidade específica por meio da qual os seres humanos aparecem uns em relação aos outros, não como objetos físicos, mas enquanto seres humanos. A palavra e a ação estão, por isso mesmo, intimamente relacionadas, existindo também uma evidente afinidade entre a palavra enquanto ação de falar e a revelação. Segundo Platão, na leitura de Hannah Arendt, a ação de falar - lexis - adere mais à verdade do que a praxis 6 , no desvendamento do ser, que surge no espaço da intersubjetividade.

Creio que o espaço de intersubjetividade privilegiado da palavra e da ação de Miguel Reale foi a grande sala de aula. Foi nela que, durante 40 anos, ele revelou a sua verdade, qual seja, a de que a Filosofia não é um simples "amor à sabedoria", mas, sim, como ele diz no fe- 
7. REALE, Miguel. Experiência e cultura. São Paulo, Grijalbo, 1977. p. 278.
8. REALE, Miguel. Teoria do direito e do Estado. 2. ed. São Paulo, Liv. Martins, 1960. p. cho de Experiência e Cultura, seguindo a lição de Dante Alighieri, "uno amoroso uso de sapienza"7.

No magistério de Miguel Reale, o que impressionou a minha geração, bem como as que nos antecederam e nos sucederam no Largo de São Francisco, foi precisamente a sinceridade de sua "amorosa experiência de sabedoria". Daí a unanimidade do respeito que o cercou, durante todos estes anos, independentemente da natural divergência de posturas e de posições provocadas pela trajetória de uma vida pública complexa e multifacetada. No espaço da sala de aula, o que surgia de sua ação de falar - de sua lexis - era um dizer brilhante e forte, porque hauria a sua autenticidade numa amorosa aventura intelectual, na qual o empenho da sabedoria sempre transcendeu a finitude das contingências e das contradições da travessia, na dignidade do nunc stans de seu pensamento.

É da dignidade desta postura que emergiu a autoridade do magistério de Miguel Reale na Faculdade de Direito da USP. Autoridade, como se sabe, envolve um acatamento que se situa no campo da hierarquia, mas que não comporta o emprego da força, já que se baseia no respeito. É por isso mesmo complexo o fundamento deste tipo de relação assimétrica, cujo sentido, no entanto, pode ser captado pela origem etimológica da palavra autoridade, que deriva do verbo latino augere - aumentar, acrescentar. Com efeito, o que os alunos sentiam face ao dizer de Miguel Reale, na grande sala de aula - que só funciona bem como espaço intersubjetivo quando um professor tem autoridade - é que, de turma para turma, de geração para geração acadêmica, ele acrescentava serenamente à universalidade do seu pensar o produto de sua proposta e de sua tensão particular de "teorizar a vida e viver a teoria na unidade indissolúvel do pensamento e da ação". É por isso que ele se converteu - e este foi o melhor resultado do seu propósito juvenil - num estadista da cultura, que soube, inclusive, quando reitor da USP, preservar a sua universidade como um espaço aberto do pensamento, numa quadra da política brasileira pós-1964 particularmente obscurantista para a cultura e a sociedade civil.

A palavra estadista origina-se do verbo latino stare - estar, estar de pé, estar firme. Creio que nenhum tema seria mais esclarecedor da interação fecunda entre pensamento e ação na reflexão de Miguel Reale - e, portanto, das razões pelas quais a sua obra está firme e de pé - do que o tema das relações entre Direito e Poder. Com efeito, nada mais central para quem está preocupado com a ação do que o poder, e nada mais pertinente, no campo da Filosofia do Direito, enquanto objeto de investigação, do inter-relacionamento entre a serenidade do pensamento e a tensão da vontade, voltada para a ação, do que as contradições e ambigüidades que caracterizam as relações entre Direito e Poder na experiência jurídica. Daí a razão da escolha do objeto deste trabalho - Direito e Poder na reflexão de Miguel Reale - tema com o qual sinto ter especial afinidade, pois, como Reale, estou igualmente convencido, depois de alguns anos de estudo e ensino de Direito Internacional Público, de que: "Estão destinadas a insucesso todas as doutrinas que procuram eliminar do Direito o conceito de "poder", ou então tentam reduzir o poder a uma "categoria jurídica pura"'8. 
9. POGGI, Gianfranco. The development of the modern state. Hutchinson, 1978. p. 723. REALE, Miguel. Teoria do direito e do Estado. 2. ed. São Paulo, Liv. Martins, 1960. p. 199-242. LAFER, Celso. Hobbes, o direito e o Estado moderno. São Paulo, Associação dos Advogados de São Paulo, 1980.

10. BOBBIO, Norberto. Teoria della norma giuridica. Torino, Giappichelli, 1958. p. 210. . Teoria dell'ordinamento giuridico. Torino, Giappichelli, 1960. p. 61-7. _. Giusnaturalismo e positivismo giuridico. 2. ed. Milano, Ed. di Comunità, 1972. p. 60-1.

Studi per una teoria generale del diritto. Torino, Giappichelli, 1970. p. 169. ___. Dalla struttura alla funzione. Milano, Ed. di Comunità, 1977, p. 132 5, 165-215.

11. CANDIDO, Antonio. Teresina, etc. Rio de Janeiro, $\mathrm{Paz}$ e Terra, 1980. p. 139.

\section{Importância do tema no pensamento jurídico- político moderno}

O complexo das relações entre Direito e Poder é um dos grandes temas da reflexão jurídico-política. No mundo moderno, essa reflexão tem ligações muito estreitas com o aparecimento do Estado, que transformou o papel do Direito. De fato, o Direito deixou de ser, como era na Idade Média, um quadro de referências da política e passou a ser, com a sua crescente positivação pelo Estado - razão explicativa das doutrinas jurídicas estatalistas - um instrumento de governo9.

Daí a proximidade entre Direito e Estado e a nova importância da dicotomia Direito Público x Direito Privado, calcada na noção de poder. Daí também a razão pela qual os juristas e jusfilósofos, que vêm pensando a realidade jurídica na perspectiva do Direito Público, tenham sido tomados pela importância da existência do Estado como instituição e como poder. Na ótica do Direito, o Estado, como instituição e organização, significa, em última instância, um conjunto de normas (o ordenamento). Estas normas estabelecem competências que permitem o exercício do poder, inclusive o de criar e aplicar normas jurídicas 10. De Hobbes e Rousseau, de Jhering, Austin e Jellineck, de Santi-Romano a Kelsen, esta é uma linha importante nas reflexões justifilosóficas.

No percurso intelectual de Miguel Reale, a primeira obra de maior ambição teórica é a Teoria do Direito e do Estado, cuja primeira èdição é de 1940. Como o próprio título indica, a linha acima mencionada foi, desde o primeiro momento, uma preocupação de Miguel Reale, preocupação que teve, biograficamente, origem na sua participação nos embates políticos da década de 30 e que, naturalmente, se aprofundou, posteriormente, em função de seu contacto e de sua experiência com os problemas de governo.

Não é minha intenção examinar, neste trabalho, a obra de Reale que abarca os anos $30 \mathrm{e}$, portanto, a sua fase integralista. Diria apenas que esses trabalhos não podem ser ignorados, inclusive no plano substantivo, pois a análise do integralismo não se esgota na crítica intelectual e na resistência política a um movimento autoritário, de grande impacto na vida nacional. Com efeito, e como salientou Antonio Candido, ao refletir sobre o clima intelectual da década de 30 , a distância do tempo mostra que, para vários jovens, o integralismo foi mais do que a negatividade de sua dimensão política. "Foi um tipo de interesse fecundo pelas coisas brasileiras, uma tentativa de substituir a platibanda liberalóide por alguma coisa mais viva" 11 .

Esta "coisa mais viva" amadurece, positivamente, em Reale, na sua obra, que se inicia em 1940, com a publicação dos já mencionados Teoria do Direito e do Estado e Fundamentos do Direito. Daí a razão da escolha do universo a ser estudado: a sua obra madura. $\mathrm{Na}$ análise, que a seguir proponho, meu objetivo é apresentar algumas notas sobre as suas reflexões a propósito das relações entre Estado, Direito e Poder na sua obra madura, tema que, como uma inquietação constante, fruto de seu propósito juvenil de "teorizar a vida e viver a teoria na unidade indissolúvel do pensamento e da ação", permeia 
12. REALE, Miguel. Filosofia do direito. 8. ed. rev. São Paulo, Saraiva, 1978. v. 2, p. 30. Experiência e cultura. São Paulo, Grijalbo, 1977. p. 278

13. REALE, Miguel. Filosofia do direito. 8 ed. rev. São Paulo, Saraiva, 1978. v. 2, p. 553. CZERNA, Renato Cirell. Reflexões didáticas preliminares à tridimensionalidade dinâmica na "Filosofia do direito". In: Teófilo Cavalcanti (org.). Estudos em homenagem a Miguel Reale. São Paulo, Rev. dos Tribunais, 1977. p. 58-9.

Ensaio de filosofia jurídica e social. São Paulo, Saraiva, 1965. p. 159-98. D'ENTRE'VES, A. Passérin. La notion de I'État. Paris, Sirey, 1969. p. 9 $11,19-81$.

14. CZERNA, Renato Cirell. Reflexões didáticas preliminares à tridimensionalidade dinâmica na "Filosofia do direito". In: _. Teófilo Cavalcanti (org.). Estudos em homenagem a Miguel Reale. São Paulo, Rev. dos Tribunais, 1977. v. 1. p. 204. toda a sua elocubração. A minha leitura tem um cunho metodológico que se estende pelas seguintes passagens: na primeira, examino a sua postura filosófica; a seguir, tento esclarecer como essa postura se desdobra numa teoria geral do Direito, seja em termos de fontes, seja em termos de hermenêutica; depois, discuto o processo de institucionalização do poder, mostrando qual é, no mundo contemporâneo, segundo Reale, o papel axiológico e sociológico da legalidade, e, finalmente, concluo com um exame do significado de sua contribuição, no contexto atual, aos estudos sobre Direito, Estado e Poder.

\section{Postura filosófica}

A Filosofia do Direito, bem como Experiência e Cultura, de Miguel Reale, são propostas voltadas para o problema do conhecimento e da experiência, para o significado e o alcance histórico-temporal do ato gnosiológico, resultante do entrelaçamento entre o sujeito cognoscente e o objeto cognoscível. O seu tridimensionalismo específi$\mathrm{co}$, no campo do Direito e do Estado, por isso mesmo, contém uma postura epistemológica - a ontognosiologia jurídica. Esta o leva a ver o fenômeno jurídico como objetivamente tridimensional, na unidade integrante de seus três elementos: fato, valor e norma ${ }^{12}$. Desta postura derivam conseqüências relevantes na apreciação de cada um desses elementos no estudo das relações entre o Direito e o Poder.

O fato, para Miguel Reale - como aponta Renato Czerna não é um dado externo indiscutível e puramente empírico. A correlação funcional sujeito/objeto realça a contribuição do sujeito na constituição do objeto. Esta contribuição resulta de uma atitude crítica, da qual provém uma concepção funcional do fato em movimento. A rejeição de uma facticidade acrítica esclarece porque ele não se filia às correntes do "realismo político", que reduzem o Direito e o Estado apenas a uma expressão de força - a força de uma decisão (decisionismo) - vendo o tema das relações entre Direito e Poder apenas à luz da efetividade das normas 13 .

Por outro lado, na perspectiva do valor, cabe dizer que o ato do conhecimento, para Miguel Reale, não é puramente lógico-formal, mas também estimativo, uma vez que existe um potencial axiológico na própria estrutura do conhecimento. Os valores deste potencial são históricos, tendo uma objetividade proveniente da totalidade do processo histórico que os põe em movimento. São características dos valores, para Miguel Reale, a sua realizabilidade na história e a sua inexauribilidade derivada da abertura, a cada momento histórico particular, ao pluralismo das possibilidades de expressão da atividade humana14. É o historicismo axiológico que explica, na obra de Reale, a razão pela qual ele não vê, no mundo atual, "poder duradouro que não se baseie sobre o consenso dos governados", posto que os valores fundantes da democracia provêm de "um processo histórico incessante de integração de valores de convivência", composto de vários legados.

São eles: (i) o legado da Grécia, ou seja, a "liberdade de pensar como pluralidade de pensar"; (ii) o de Roma, que se traduz na consciência dos valores autônomos do Direito como algo mais amplo do 
15. REALE, Miguel. Pluralismo e liberdade. São Paulo, Saraiva, 1963. p. 224, 287. Teoria tridimensional do direito. 2. ed. rev. São Paulo, Saraiva, 1979. p. 79-89.

16. REALE, Miguel. Pluralismo eliberdade. São Paulo, Saraiva, 1963 . v. 2, p. 546-57. Filosofia do direito. 8. ed. rev. São Paulo, Saraiva, 1978. v. 2, p. 546-57. FERRAZ JUNIOR, Tércio Sampaio. A noção da norma jurídica na obra de Miguel Reale. Ciência e cultura. 26 (2): 1011-6, nov. 1974.

17. REALE, Miguel. O direito como experiência. São Paulo, Saraiva, 1968. p. 197. que a consciência da lei. Sem esta consciência dos valores autônomos do Direito, que permite afastar "a idéia do arbítrio" , observa Reale, "poderá existir ordem e disciplina, mas não existirá democracia"; (iii) o legado do cristianismo, representado pelo reconhecimento da igualdade da natureza humana independentemente dos particularismos dos invólucros políticos e sociais da cidadania; (iv) o legado do /iberalismo, ou seja, a noção de Estado de Direito, na qual, graças ao constitucionalismo, a prudente distribuição de competências no âmbito do Estado enseja a fiscalização dos atos do Executivo, que evita o abuso do poder; e, finalmente, (v) o legado do socialismo, do qual se origina uma exigência de igualdade perante a vida e a cultura, entendida como direito reconhecido a cada homem de participar do "bemestar social", daquilo que a espécie humana, num processo coletivo, vai acumulando através do tempo15.

São estas constantes axiológicas no processo de integração dos valores de convivência - verdadeiro fio subjacente à reflexão de Miguel Reale sobre o fundamento das relações entre Direito e Poder que o levam a tratar do assunto tendo como horizonte a legitimidade do poder e a justiça da norma.

Finalmente, quanto à norma, esta é apreciada lato sensu como uma expressão dialética que integra, em cada situação histórica, de maneira mais ou menos duradoura, mas nunca definitiva, fato e valor. Essa integração envolve uma escolha: a opção por um caminho dentre múltiplos caminhos possíveis. Tal escolha, que resulta da necessidade de um ato hierárquico de gestão, no processo de elaboração normativa, dá-se através da interferência decisória do poder 16 .

Nas palavras de Reale, "não surge norma jurídica sem ato decisório, mas também inexiste ato decisório absoluto, não condicionado, em maior ou menor grau, por um quadro de possibilidades normativas. Se será exagero afirmar-se que o poder não passa de um momento subordinado ao processo de objetivação normativa, não resta dúvida que não há poder que não seja condicionado pelo "plexo fático-axiológico" de cada campo de relações sociais"17. Este processo, no qual a estimativa de realizabilidade dos valores revela o Reale preocupado com os limites possíveis da ação em cada situação particular, e a consciência da inexauribilidade dos valores, o Reale pensador ciente da finitude do homem concreto diante da História, evidencia-se, na experiência do Direito, num momento paradigmático: o da nomogênese jurídica. Por essa razão, pode-se dizer que a correlação essencial entre Direito e Poder transita, inicialmente, na reflexão de Miguel Reale, em termos de sua teoria geral do Direito, por uma análise das fontes.

\section{Teoria Geral do Direito}

\subsection{Fontes}

O tema das fontes do Direito é um dos problemas cruciais da reflexão jurídica. Em O Direito como Experiência, Miguel Reale propõea substituição da teoria das fontes pela dos modelos jurídicos, tendo em vista a sua concepção tridimensional do Direito como o produto 
18. REALE, Miguel. O direito como experiência. São Paulo, Saraiva, 1968. p. 147-73. LAFER, Celso. O sistema político brasileiro. 2. ed., São Paulo, Perspectiva, 1978. p. 19-58.

19. REALE, Miguel. Pluralismo e liberdade. São Paulo, Saraiva, 1963. p. 197.

20. REALE, Miguel. Pluralismoe liberdade. São Paulo, Saraiva, 1963. p. 220-2.

Teoria do direito e do Estado. 2. ed., São Paulo, Liv. Martins, 1960. p. 302 . _. Estudos de filosofia e ciência do direito. São Paulo, Saraiva, 1978. p. 35-51. dialético inseparável do fato, do valor e da norma. Nas teorias clássicas das fontes formais e materiais, aponta ele, existe uma visão excessivamente comportamentalizada de fato, valor e norma, e também uma ótica retrospectiva e não prospectiva do Direito - que não capta as necessidade de mudança do Direito em sociedades em permanente transformação, como são as sociedades modernas, e que não atende também, poder-se-ia dizer, à inquieta vontade de ação inerente à proposta de vida de Miguel Reale.

Os modelos jurídicos estruturam-se, de acordo com Miguel Reale, graças à integração de fatos e valores, segundo normas postas em virtude de um ato de escolha. Este ato de escolha exprime uma função hierárquica de gestão da sociedade, necessária dada a multiplicidade possível de caminhos de integração, uma vez que inexiste verdade única, transpessoal e definitiva. $\mathrm{O}$ ato de escolha e de gestão, que impede a paralisia decisória e a entropia e permite a elaboração normativa, pode resultar de opções costumeiras, da vontade do legislador, da decisão do juiz ou de estipulações fundadas na autonomia da vontade18. Esse ato de escolha é, ontologicamente, um momento de poder, na experiência jurídica.

Com efeito, para ser dotada de validade objetiva, isto é, de efetividade para outrem (heteronomia), a norma, enquanto diretriz de conduta, requer - como se evidencia com clareza na experiência do Direito Internacional - o poder, ainda que descentralizado, como categoria de realizabilidade do Direito 19.

Os modelos jurídicos, assim elaborados por meio da interferência decisória do poder, têm distintos índices de obrigatoriedade e áreas diversificadas de incidência. A sua positividade está correlacionada a uma gradação de poder. A soberania, como o poder de declarar, em última instância, a positividade do Direito, significa para Miguel Reale que o Estado, no mundo moderno, é o centro geométrico da positividade jurídica, sem prejuízo do pluralismo dos modelos jurídicos20. Desta maneira, na sua reflexão sobre as fontes do Direito, que leva em consideração, sem dúvida, a sua prática de advogado militante, Reale dá conta da multiplicidade e da eventual e ambigua incoerência dos modelos jurídicos que a experiência jurídica vai elaborando em função de vários fatores. Tais modelos incluem os elaborados pelo Direito das Gentes, provenientes da necessidade de mútua colaboração dos Estados no âmbito internacional, e cuja positividade advém tanto da permanência da reciprocidade dos interesses que os motivaram, quanto da estruturação das relações entre ordem e poder, em cada momento histórico da vida da sociedade internacional.

Abrangem também os modelos derivados da estruturação do poder privado, seja os de alcance transnacional - como, por exemplo, a nova "lex mercatoria" da empresa multinacional, seja os de alcance transnacional e nacional, como os de poder de controle nas sociedades anônimas, tão bem estudados por Fábio Konder Comparato. Incluem, igualmente, os que resultam do desdobramento da ação intervencionista do Estado. Estes últimos, Miguel Reale examina-os em estudo recente, sugestivamente intitulado "O 'Duplo' do Estado" , no qual aponta os riscos e as contradições de uma dispersão 
21. COMPARATO, Fábio Konder. O poder de controle nas sociedades anônimas. 2. ed., São Paulo, Rev. dos Tribunais, 1977. REALE, Miguel. O homem e seus horizontes. São Paulo, Convívio, 1980. p. 149-57. RIGAUX, François. Pour un autre ordre international. In: Droit economique II. Paris, Pedone, 1979. p. 288-337. LAFER, Celso. Comércio e relações internacionais. São Paulo, Perspectiva, 1977. p. 11-37, 65-88. convênio do café de 1976. São Paulo, Perspectiva, 1979. p. 7 69.

22. REALE, Miguel. Pluralismoe liberdade. São Paulo, Saraiva, 1963, p. 217.

23. REALE, Miguel. O direito como experiência. São Paulo, Saraiva, 1968. p. 247.

24. REALE, Miguel. O direito como experiência. São Paulo, Saraiva, 1968. p. 232 e 243. Estudos de filosofia e ciência do direito. São Paulo, 1978. p. $72-82$.

25. REALE, Miguel. Pluralismoe liberdade. São Paulo, Saraiva, 1963. p. 216-7. WEBER, Max. On law in economy and society. Ed. por Max Rheinstein. Trad. de Edward Schils. Combridge, Harvard UniversityPress, 1954.

26. FERRAZ JUNIOR, Tércio Sampaio. Direito, retórica e comunicação. São Paulo, Saraiva, 1973. p. 33-5. na ação governamental que ameaça o Estado, inclusive o brasileiro, enquanto centro geométrico da positividade jurídica21.

A norma posta pela interferência decisória do poder convertese numa intencionalidade objetivada, pois, para Miguel Reale, "'a norma jurídica é sempre uma medida racional ou teleológica de conduta ou de organização". A ação objetivante do poder, no campo do Direito22, requer um exame do ato interpretativo e do poder, posto que, para Reale, "à luz de um normativismo concreto, ato normativo e ato interpretativo são elementos que se co-implicam e se integram, não se podendo, senão por abstração e como linha de orientação da pesquisa, separar a regra e "a situação regulada" 23 .

\subsection{Hermenêutica}

Toda época, aponta Miguel Reale, fixa as normas e os limites de șa exegese do Direito em função de valores culturais prevalecentes. É por essa razão que, por exemplo, no século XIX, à concepção do Estado Liberal não-intervencionista corresponde uma compreensão restrita e negativa da hermenêutica jurídica, compreensão essa substituída, no século atual, pelas exigências de uma nova hermenêutica, intervencionista como o Estado no século XX.

No mundo contemporâneo, as múltiplas e complexas intencionalidades objetivadas nas normas, postas pelo ato decisório do poder, estão sempre na dependência do ato interpretativo. Com efeito, é na situação específica regulada pela interpretação que se verifica o sentido concreto de que se reveste uma totalidade de sentidos possiveis, compreendidos nos diversos modelos jurídicos. Miguel Reale examina algumas das notas distintivas da hermenêutica contemporânea, por ele denominada interpretação estrutural. Para os propósitos deste trabalho, fixo-me apenas em duas: (i) os limites objetivos do processo hermenêutico, pois a atividade interpretativa tem a sua liberdade limitada pela fidelidade às intencionalidades objetivadas da norma; e (ii) a natureza racional do ato interpretativo concreto, pois os modelos jurídicos são entidades lógicas, válidas segundo exigências racionais, ainda que estas, na experiência jurídica, sejam as do razoável, que leva em conta fatos e valores 24.

As duas notas apontadas ligam-se à dimensão objetivante do poder no campo do Direito contemporâneo, que visa a reduzir o arbítrio, inclusive o do intérprete, em obediência ao princípio de racionalidade legal. Este, como observou Max Weber, é o tipo ideal de legitimidade que permeia a evolução dos padrões de autoridade no mundo moderno25. Isto, em síntese, significa que o intérprete não pode apenas afirmar, mas deve igualmente justificar a sua decisão, prestando contas às partes e à comunidade da razoabilidade da sua tomada de decisão26.

A dimensão objetivante do poder, colocada ao intérprete pela norma posta, não esgota, no entanto, a análise da relação entre Direito e Poder no momento da aplicação normativa. Toda norma, no momento em que é aplicada, sempre comporta mais de uma interpretação. O ato decisório da escolha e da opção por uma interpretação, ainda que fundamentado racionalmente e balizado pelos limites da hermenêutica estrutural, é também um ato de poder. 
27. LAFER, Celso. Ensaios sobre a liberdade. São Paulo, Perspectiva, 1980. p. 25-30.

28. FERRAZ JUNIOR, Tércio Sampaio. Direito, retórica e comunicação. São Paulo, Saraiva, 1973. p. 33-5

A Ciência do Direito. São Paulo, Atlas, 1977. p. 87 103.
A positividade de uma interpretação, assim como a positividade da norma, está ligada a uma gradação de poder. É por essa razão que a solução judicial de controvérsias no plano internacional é complexa, dada a distribuição individual de poder entre os Estados, e é por isso que, no âmbito interno, a prestação jurisdicional é uma dimensão da soberania. O Estado, ao avocar a si o poder de declarar em última instância a positividade de uma interpretação (por exemplo, por intermédio do Supremo Tribunal Federall), busca manter-se como o centro geométrico da positividade jurídica. Naturalmente, isto não exclui a possível pluralidade de interpretações e aplicações normativas previstas nos modelos jurídicos e admitidas pelo ordenamento jurídico estatal ou internacional, no contexto do "plexo fático-axiológico".

Esclareceria, neste sentido, que a dimensão ontológica da relação entre Direito e Poder, tanto no ato normativo, quanto no interpretativo, pode ser adequadamente apreendida por uma rápida referência às características do discurso jurídico, tal como as vem analisando Tércio Sampaio Ferraz Jr.

O discurso da experiência jurídica tem como objeto um dubium conflitivo. Este dubium é dialógico, tanto no momento que antecede a nomogênese jurídica - que são as diversas propostas normativas - quanto no momento que antecede a sentença - que são, como se pode entender, as alegações das partes em virtude do princípio do contraditório. O discurso, no entanto, converte-se, necessariamente, num monólogo pela interferência decisória do poder. Esta éa maneira pela qual o dubium, que é objeto do discurso jurídico, se converte num certum: na nomogênese jurídica, através da certeza da norma posta, caminho escolhido entre muitas propostas normativas possíveis, dadas, em cada circunstância histórica, pelo "plexo fáticoaxiológico"; na aplicação da norma, pela sentença revestida de autoridade de coisa julgada, que, no espectro das intencionalidades objetivadas pelas normas postas, representa também uma interpretação entre muitas possíveis, dadas pelo "plexo fático-axiológico". De fato, é da natureza do discurso jurídico pôr fim a um conflito, solucionando-o não por meio do caminho de mão única da evidência, que inexiste no campo das ciências humanas27, mas, sim, terminando-o, num dado momento, através de uma decisão, seja sobre a norma que deve ser posta, seja sobre a sua interpretação. Essa decisão, para ter validade objetiva "erga omnes", exige, ontologicamente, o poder como categoria de sua realizabilidade 28 .

\section{O papel da legalidade e da legitimidade}

Estes apontamentos sobre as relações entre Direito e Poder, na reflexão de Miguel Reale, não ficariam adequadamente balizados em seus contornos, se referência não fosse feita também à dimensão deontológica do problema, ou seja, à aspiração de que o poder, no mundo contemporâneo, subordine-se ao Direito. Efetivamente, no jogo da dialética de implicação e polaridade, que governa a reflexão de Miguel Reale, valor e realidade pressupõem-se em relação de mútua complementaridade. Daí a importância de um exame da imbricação entre o plano ontológico e o sociológico lo poder como categoria 
29. REALE, Miguel. Pluralismo eliberdade. São Paulo, Saraiva, 1963 . v. 2 , p. 365. Teoria tridimensional do direi to. 2. ed. rev. São Paulo, Saraiva, 1979. p. 67-77.

30. REALE, Miguel. Teoria do direito e do Estado. 2. ed. São Paulo, Liv. Martins, 1960. p. 76-7.

31. KELSEN, Hans. General theory of law and state. New York, Russel and Russel, 1961. p. 112-4. The pure theory of law and state. 2. ed. Berkeley, University of California Press. p. 195-8. REALE, Miguel. Pluralismo e liberdade. São Paulo, Saraiva, 1963. p. 220-35. Filosofia do direito. 8. ed. rev. São Paulo, Saraiva, 1978. p. 465-9.

32. BOBBIO, Norberto. Studi per una teoria generale del diritto. Torino, Giappichelli, 1970. p. 175-97. HART, H.L.A. The concept of law. New York, Oxford University Press, 1961. p. 77-96. LAFER, Celso. Hobbes, o direito e o Estado moderno. São Paulo, Associação dos Advogados de São Paulo, 1980. p. 31-3.

33. BOBBIO, Norberto. Teoria della norma giuridica. Torino, Giappichelli, 1958. p. 211 . 2. Studi per una teoria generale del diritto. Torino, Giappichelli, 1970. p. 83. LAFER, Celso. Ensaios sobre a liberdade. São Paulo, Perspectiva, 1980. p. 58-9. REALE, Miguel. Politica de ontem e de hoje. São Paulo, Saraiva, 1978. p. $77-89$. de realizabilidade do Direito) e o plano deontológico, o qual, no caso, para os efeitos deste trabalho, poderia ser resumido em torno da legitimidade da aspiração ao Estado de Direito29.

Desde a Teoria do Direito e do Estado, vem Miguel Reale se preocupando com os processos de institucionalização progressiva do poder. Uma das dimensões desse processo é a sua jurisfação, ou seja, a juridicidade progressiva de que se reveste o poder, no mundo contemporâneo 30 . A jurisfação, que não anula, evidentemente, o poder, pode ser analisada recorrendo-se ao que Kelsen chamou de princípio dinâmico do Direito, em virtude do qual as normas são conhecidas, identificadas e qualificadas como jurídicas pelo modo como são produzidas 31 .

Num ordenamento que obedece ao princípio dinâmico, que por sua vez corresponde, sociologicamente, às necessidades de contínua adaptação dos modelos jurídicos às realidades em permanente transformação, o fundamental não é o estudo das assim chamadas normas primárias, que são as que prescrevem, proscrevem, estimulam ou desestimulam comportamentos e que têm como destinatários os membros de uma sociedade. Na experiência jurídica das sociedades modernas, ao contrário do que ocorria - e ocorre - nas sociedades tradicionais, as normas primárias estão em contínua e rápida mudança. É por essa razão que, do ponto de vista da jurisfação do poder, o importante é o exame das normas secundárias, isto é, das normas sobre normas, que são, basicamente, as que tratam, ou da produção das normas primárias, ou do modo como estas são aplicadas. É através da existência, do acatamento e da permanência institucional das normas secundárias que se disciplina a interferência decisória do poder, no momento ontologicamente conclusivo, da criação e aplicação do Direito32.

De fato, uma das maneiras de se assinalar a conversão do Estado absolutista e arbitrário num Estado de Direito é a extensão progressiva do Direito, da base para o vértice da pirâmide jurídica, isto é, dos governados para os governantes. Tal processo, que marca a passagem e a substituição da decisão arbitrária pela decisão juridicamente controlada e disciplinada, é uma das conquistas da técnica do Estado de Direito e da reflexão liberal. É através das normas secundárias, que têm como destinatários os que exercem o poder, que se jurisfaz 0 poder. É por isso que se pode dizer, com Bobbio, que a legalidade é uma qualidade do exercício do poder, uma vez que impede a tyrannia quoad exercitium, interessando, por isso mesmo, antes aos governados do que aos governantes33. Por interessar aos governados é que a aspiração deontológica da subordinação do poder ao Direito representa um dos ingredientes do consenso, fundamento da dimensão ontológica da relação entre Direito e Poder no mundo contemporâ-
neo.

O consenso, enquanto processo público e coletivo de legitimação do poder, cresce, evidentemente, na medida em que as normas secundárias de criação e aplicação do Direito são tidas como justas pela comunidade, através do modo como atendem às múltiplas e conflitantes aspirações e reivindicações de seus membros. De fato, 
34. BARBE, Carlo. Appunti per una teoria della legittimazione. Torino, Giappichelli, 1973. p. 41-2. LAFER, Celso. Hannah Arendt - Pensamento, Persuasão e Poder. Rio de Janeiro, Paz e Terra, 1979. p. 358. A LEGITIMIDADE na perspectiva histórica; comentários. Universidade de Brasília. In: Encontros internacionais da UnB. Brasília, 1980. p. 319 25 .

35. D'ENTRÉVES, A. Passérin. La notion de l'État. Paris, Sirey, 1969. p. 9-12.

36. BOBBIO, Norberto, Giusnaturalismo e positivismo giuridico. 2. ed. Milano, Ed. di Comunità, 1972. p. 60-1. na legitimação do poder existem os legitimados e os legitimantes. A legitimação é fruto da interação entre governantes governados, que resulta da concordância com um curso comum de ação em virtude de um incessante processo de integração dos valores de convivência. 0 "pacto social" exprime esta concordância, quando faz atuar, num dado momento histórico, os valores delineados como modelo de vida pela comunidade34. Na evolução das sociedades contemporâneas, esta correspondência transita pelas normas secundárias, examinadas não apenas na sua dimensão abstrata e lógica, como o fazem Kelsen e Hart, mas também em função do seu conteúdo concreto. Com efeito, é pela proposta de estudo de seu conteúdo concreto que o historicismo de Miguel Reale, atento aos legados axiológicos que fundamentam a democracia, no jogo de sua dialética de implicação e polaridade, capta ser e deve ser, dimensão deontolǵica de um lado, e dimensão ontológica e sociológica de outro, nas relações entre Direito e Poder.

\section{Conclusão}

A. Passérin d'Entrèves, no seu importante livro sobre o Estado, encarado na perspectiva das relações entre o Direito e o poder, distingue três aspectos do Estado: (i) o Estado como força, que é o ponto de vista do "realismo político"; (ii) o Estado como "poder" stricto sensu, isto é, como uma força qualificada pelo Direito, força submetida à lei, que é a perspectiva da teoria jurídica e do normativismo abstrato; e, finalmente, (iii) o Estado como autoridade, graças à qual a força, legalizada enquanto poder, se legitima35. Há, portanto, na reflexão de Passérin d'Entrèves, uma perspectiva tridimensional, pois a força corresponde ao fato, o poder à norma e a autoridade ao valor.

Por outro lado, Norberto Bobbio, ao examinar os diversos campos da Filosofia do Direito, lembra que, na verdade, eles são três: (i) a reflexão sobre a reforma e a transformação da sociedade orientada por certos valores, como a liberdade, a ordem, a igualdade, o bemestar. É a Filosofia do Direito concebida como Filosofia Política e Teoria da Justiça, ou seja, como Deontologia; (ii) a análise e a definição de noções gerais, que todos os ordenamentos jurídicos contêm e que permitem delimitar o campo do Direito, distinguindo-o de outros, como, por exemplo, a Moral - é a Filosofia do Direito encarada como Teoria Geral do Direito, ou seja, Ontologia, que examina temas como validade, eficácia, direito subjetivo etc.; e, por fim, (iii) o estudo do Direito enquanto fenômeno de controle social; é a Filosofia do Direito vista como Sociologia Jurídica.

Bobbio também menciona um quarto campo, que seria o da Metodologia Jurídica, que vem tendo, hoje em dia, grande desenvolvimento, sobretudo na área da linguagem do Direito, lembrando ele a escola da "Nouvelle Rhétorique", que renovou a lógica e a epistemologia da experiência jurídica36. Este quarto campo, no entanto, ou é fruto de uma prévia atitude epistemológica, ou se desdobra enquanto área da Teoria Geral do Direito. É por isto que se pode concluir que, também na perspectiva de Bobbio, existe uma visão tridimensional da Filosofia do Direito, pois a Deontologia corresponde ao valor, a Onto- 
37 REALE, Miguel. Teoria tridimensional do direito. 2. ed. rev. São Paulo, Saraiva, 1979. p. 28-30.

38. REALE, Miguel. Teoria do direito e do Estado. 2. ed. São Paulo, Liv. Martins, 1960. p. 346.

39. REALE, Miguel. Teoria do direito e do Estado. 2. ed. São Paulo, Liv. Martins, 1960. v. 2 , p. 345. Filosofia do direito. 8. ed. rev. São Paulo, Saraiva, 1978 . v. 2 , p. 557. logia à norma e a Sociologia Jurídica ao fato37. Daí a conclusão de Miguel Reale, no sentido de apontar que todo conhecimento do Direito e do Estado "é necessariamente tridimensional: o que se verifica em cada âmbito particular de estudo é apenas o predomínio vetorial de um dos três fatores, distinguindo-se cada indagação pelo sentido de seu desenvolvimento38.

Existe, no entanto, do ponto de vista de uma reflexão sobre o poder, um risco na tridimensionalidade articulada sem interconexões mais profundas. De fato, este tipo de articulação não é o mais propício para captar a dimensão problemática de que se revestem o Estado e o Direito num mundo como o atual, assinalado pelos dilemas da necessidade de compatibilizar as estruturas jurídicas e políticas com as aspirações quotidianas da convivência humana.

Na perspectiva tridimensional, articulada apenas de maneira sistemática, o poder tende a ser encarado: ou (i) como um dado externo à norma - que é atitude freqüente nas correntes positivistas; ou (ii) como um dado independente da norma - que é atitude freqüente na Ciência Política ou na Sociologia Jurídica; ou, ainda, (iii) como meio para se alcançar a norma desejável - que é atitude freqüente na Deontologia. Daí a relevância da passagem de um tridimensionalismo abstrato para um tridimensionalismo concreto, tal como propõe Miguel Reale, que internaliza o poder na norma. Em virtude de sua postura metodológica - o quarto campo mencionado por Bobbio, aqui entendido como Epistemologia - introduz ele o problema do poder no sistema do Estado e do Direito, inclusive o privado, problematizando-os de uma forma aberta. Bastaria, aliás, lembrar, na área do Direito Privado, a título de ilustração, os dilemas dos sistemas de poder de controle na sociedade anônima. Com efeito, é isto que ele esclarece, de maneira geral, ao iluminar as modalidades por meio das quais, num dado momento, os dilemas do enlace fáticoaxiológico convertem-se nưm sistema de normas e de sua aplicação, por meio da mediação do poder39. Entretanto, este sistema, ao ser governado por uma dialética de implicação e polaridade, nunca é fechado, mas, sim, aberto nas suas transformações e aplicações aos dilemas suscitados pela cisão entre as estruturas, as aspirações de convivência e as realidades cambiantes do poder.

Foi isto que tentei esboçar neste trabalho, partindo, em primeiro lugar, de uma análise de sua posição filosófica (a ontognosiológicojurídica); vendo, a seguir, como ela se desdobra numa teoria geral do Direito, seja em termos de fontes (os modelos jurídicos), seja em termos de hermenêutica (a interpretação estrutural); concluindo, afinal, pelo exame do papel das normas secundárias no processo de jurisfação do poder. Nesta última passagem, tentei esclarecer como, no jogo da dialética de implicação e polaridade, ser (ontologia do poder) e dever ser (deontologia do poder) se entrelaçam em relação de mútua complementaridade.

Para concluir, direi que este esquema, quase que descarnado na descrição das etapas analíticas, das relações entre Estado, Direito e Poder, na obra de Reale, só adquire a sua dimensão exata de conteúdo a partir da distinção de Dilthey entre o explicar e o compreender. 
40. REALE, Miguel. Experiência e cultura. São Paulo, Grijalbo, 1977. p. 69-70, 172-3.

CZERNA, Renato Cirell. Expe rienza e cultura in Miguel Reale. Rivista Internazionale di Filosofia del Diritto, 61 (4): 531 48, out./dez., 1979

41. REALE, Miguel. Filosofia do direito. 8. ed. rev. São Pau Io, Saraiva, 1978 v. 1, p. $240-$ 56.

42. ARENDT, Hannah. Compreension et politique. Esprit, (42): 66-79, jun., 1980.

43. REALE, Miguel. Filosofia do direito. 8. ed. rev. São PauIo, Saraiva, 1978 . v. 1, p. 228 30. SPRANGER, Edward. Formas de vida. Trad. Ramón de la Serna. Buenos Aires, Rev. de Ocidente Argentina, 1946. BOBBIO, Norberto. Giusnaturalismo e positivismo giuridico. 2. ed., Milano, Ed. di Comunità, 1972. p. 43-6.
Com efeito, o culturalismo, que é uma das importantes matrizes do pensamento de Miguel Reale, diferencia o explicar - a busca dos nexos necessários de antecedente e conseqüente, aptos a esclarecer a estrutura dos fatos - e o compreender, que envolve o explicar, na totalidade dos seus fins, esclarecendo as suas conexões de sentido 40 . Dai a recusa do positivismo, que busca dissolver a Teoria do Conhecimento numa Teoria da Ciência, bem como a rejeição do divórcio kantiano entre razão pura e razão prática, que compromete - no entender de Miguel Reale - "a verdade em germe na Filosofia Crítica, que é a originalidade do espírito como síntese "a priori" transcendental, que condiciona tanto a explicação da natureza como a compreensão da História"41.

A compreensão, como se sabe, é um processo complexo e sem fim porque tem como objetivo, ao buscar sentido, ajustar-nos à realidade e reconciliar-nos com as nossas ações e as nossas paixões. Esta busca de sentido - ao contrário do raciocínio lógico matemático, que é uma aptidão humana interna, do homem na sua singularidade - exige o senso comum, ou seja, a percepção do Outro, no mundo compartilhado da intersubjetividade 42 . O Direito e o Poder existem no campo da intersubjetividade de um mundo em comum. Por esse motivo, são fenômenos que não podem ser captados, no seu perfil próprio, pelo "homo theoreticus" da reflexão de Spranger, que vive no mundo abstrato das leis da objetividade. Nisso reside, talvez, a razão pela qual as maiores contribuições à Filosofia do Direito contemporânea tenham como origem juristas com interesses filosóficos e nãofilósofos com curiosidade jurídica. Por outro lado, o "homo politicus", fustigado pela vontade, voltada para o futuro das razões inflexíveis de poder, raramente tem tempo para parar e pensar, traduzindo numa obra intelectual o seu esforço de compreensão particular da situação em que se movimenta 43 .

O entendimento amplo do Direito exige, por isso mesmo, um tipo complexo de personalidade, que obedece a uma combinatória mista de polarizações valorativas, interessadas tanto na teoria, quanto na prática. A proposta de Reale de "teorizar a vida e viver a teoria" representa, precisamente, uma combinatória mista de polarizações valorativas, aptas a lidar com o inter-relacionamento entre Direito e Poder. Daí a razão pela qual, a partir de um núcleo de idéias básicas a tridimensionalidade específica - que conferem coerência à sua pesquisa, vem ele, através de aproximações sucessivas, buscando esclarecer, no processo complexo e sem fim da compreensão, as relações entre Direito e Poder. Estas relações, por não se assinalarem pela univocidade, são irredutíveis a uma categoria pura - a uma sintaxe.

Comportam, no entanto, uma semântica e uma pragmática. Estas, na reflexão de Reale, guiadas pela razão enquanto idéia regulativa, ainda que histórica e socialmente condicionada, conjugam-se pela gramática do historicismo axiológico e pela dialética de implicação e polaridade, ambas conduzidas pelo horizonte aberto da noção jurídica de legitimidade, entendida como uma ponte civilizatória entre o poder e o medo, sem o qual a vida, na sociedade humana, perde a sua dignidade. 
1. ARENDT, Hannah, Compreension et politique. Esprit, (42): 66-79, jun. 1980.

2. ,The human condition. Chicago, The University of Chicago Press, 1958.

3. BARBĖ, Carlo. Appunti per una teoria della legittimazione. Torino, Giappichelli, 1973.

4. BOBBIO, Norberto. Dalla struttura alla funzione. Milano, Ed. di Comunità, 1977.

5. G_ Giusnaturalismo e positivismo giuridico. 2. ed., Milano, Ed. di Comunità, 1972.

6. Studi per una teoria generale del diritto. Torino, Giappichelli, 1970.

7. Teoria della norma giuridica. Torino, Giappichelli, 1958.

8. Teoria dell'ordinamento giuridico. Torino, Giappichelli, 1960

9. CANDIDO, Antonio. Teresina, etc. Rio de Janeiro, Paze Terra, 1980

10. COMPARATO, Fábio Konder. O poder de controle nas sociedades anônimas. 2. ed. São Paulo, Rev. dos Tribunais, 1977.

11. CZERNA, Renato Cirell. Ensaio de filosofia jurídica e social. São Paulo, Saraiva, 1965.

12. Esperienza e cultura in Miguel Reale. Rivista Internazionale di Filosofia del Diritto. 61 (4): 531-48, out./dez. 1979.

13. Reflexões didáticas preliminares à tridimensionalidade dinâmica na "Filosofia do Direito". In: - Teófilo Cavalcanti (org.). Estudos em homenagem a Miguel Reale. São Paulo, Rev. dos Tribunais, 1977.

14. D'ENTREVES, A. Passèrin. Lanotion de l'Etat. Paris, Sirey, 1969.

15. FERRAZ JUNIOR, Tércio Sampaio. A ciência do direito. São Paulo, Atlas, 1977.

16. Direito, Retórica e Comunicação. São Paulo, Saraiva, 1973.

17. A noção da norma jurídica na obra de Miguel Reale. Ciência e Cultura. 26 (2): 1011-6, nov. 1974.

18. HART, H.L.A. The concept of law. Nova York, Oxford University Press. 1961.

19. KELSEN, Hans. General theory of law and state. Trad. de Anders Wedberg. Nova York, Russel and Russel, 1961.

20. The pure theory oflawand state. 2. ed., Trad. de Max Knight. Berkeley, University of California Press. 1967.

21. LAFER, Celso. Comércio e relacões internacionais. São Paulo, Perspectiva, 1977

22. Oconvênio do café de 1976. São Paulo, Perspectiva, 1979.

23. Ensaios sobre a liberdade, s.n.t.

24. Hannah Arendt - Pensamento, Persuasão e Poder. Rio de Janeiro, Paze Terra, 1979.

25. Hobbes, o direito e o Estado moderno. São Paulo. Associação dos Advogados de São Paulo, 1980.

26. Saudação do bacharelando Celso Lafer. Revista da Faculdade de Direito da USP. São Paulo, 60(1):361-64, 1965

27. O sistema político brasileiro. 2. ed. São Paulo, Perspectiva, 1978.

28. A LEGITIMIDADE na perspectiva histórica; Comentário. Universidade de Brasília. In: Encontros internacionais da UnB. Brasília, 1980

29. POGGI, Gianfranco. The development of the modern state. SL, Hutchinson, 1978. 
29. A LEGITIMIDADE na perspectiva histórica; Comentário. Universidade de Brasília. In: Encontros internacionais da UnB. Brasilia, 1980.

30. POGGI, Gianfranco. The development of the modern state. SL, Hutchinson, 1978.

31. REALE, Miguel. Odireito como experiência. São Paulo, Saraiva, 1968.

32. REALE, Miguel. Estudos de filosofia e ciência do direito. São Paulo, Saraiva, 1978.

33. REALE, Miguel. Experiência e cultura. São Paulo, Grijalbo, 1977.

34. REALE, Miguel. Filosofia do direito. 8 ed. rev. São Paulo, Saraiva, 1978.

35. REALE, Miguel. O homem e seus horizontes. São Paulo, Convívio, 1980.

36. REALE, Miguel. Pluralismo e liberdade. São Paulo, Saraiva, 1963.

37. REALE, Miguel. Politica de onteme de hoje. São Paulo, Saraiva, 1978.

38. REALE, Miguel. Teoria do direito e do Estado. 2. ed. São Paulo, Liv. Martins, 1960.

39. REALE, Miguel. Teoria tridimensional do direito. 2. ed. rev. São Paulo, Saraiva, 1979.

40. RIGAUX, François. Pour un autre ordre international. In. Droit économique - II. Paris, Pedome, 1979.

41. SPRANGER, Edward. Formas de vida. Trad. Ramón de la Serna. Buenos Aires, Rev. de Ocidente Argentina, 1946.

42. WEBER, Max. On law in economy and society. Ed. por Max Rheinstein. Trad. de Edward Schils. Cambridge, Harvard University Press, 1954. 